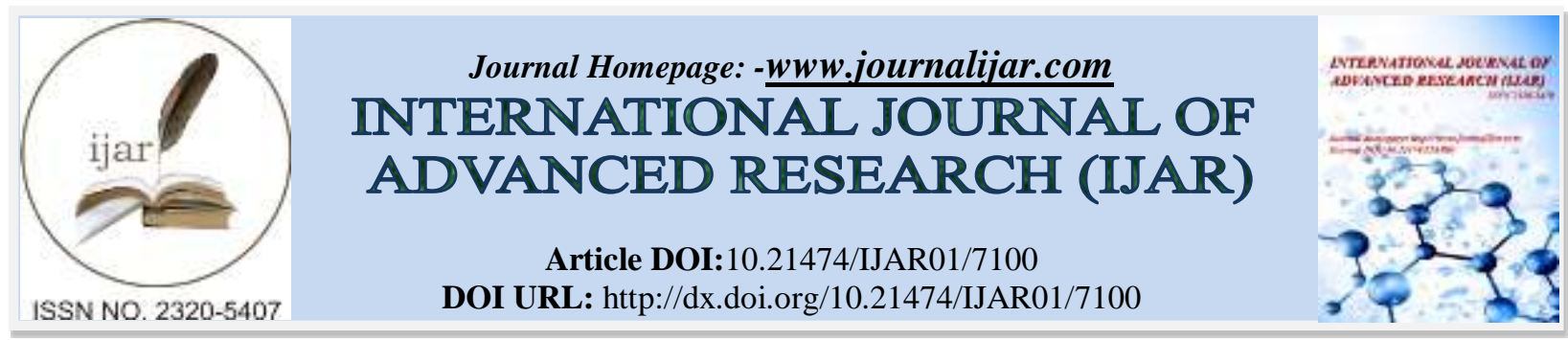

RESEARCH ARTICLE

\title{
A SURVEY OF INJURIES TO THE ANTERIOR CRUCIATE LIGAMENT AMONG MAKKAH POPULATION, SAUDI ARABIA: PREVALENCE AND OBSERVATIONS ON INJURY MECHANISM.
}

\author{
Maram Alrubayyi $^{1}$, Seham Alzahrani ${ }^{2}$, Areej Alotaibi ${ }^{2}$, Afrah Albalawi ${ }^{2}$, Malak Asiri ${ }^{2}$, Sumayah Alzahrani $^{2}$, \\ Amal Alotaibi ${ }^{2}$ and Shareefah Alenezi ${ }^{2}$. \\ 1. Medical Student, Tabuk University, College of Medicine, Tabuk City, Saudi Arabia. \\ 2. Medical Student, Tabuk University, College of Medicine, Tabuk City, Saudi Arabia.
}

\section{Manuscript Info}

Manuscript History

Received: 14 March 2018

Final Accepted: 16 April 2018

Published: May 2018

Keywords:-

Anterior Cruciate Ligament Injury,

Sports Injury, Knee Injurie.

\section{Abstract}

Objective: To estimate the prevalence, risk factor and mechanism of Anterior Cruciate Ligament Injury among Makkah city, Saudi Arabia.

Design and Setting: A survey reviews the prevalence and the mechanisms of anterior cruciate ligament (ACL) injury. We used a multiple questionnaire, carry out a 266 from the population were interviewed about the events surrounding their ACL injury.

Results: The most common injury of ACL was sport $(n=181)$. ACL injury occurred due to a sudden increase in running $(n=18)$ and due to stop running suddenly $(n=20)$.four-teen of them did not report whether their injury occurred in a practice or in a game. Sixteen were listed as road traffic accident and 14 as related to their work. Noncontact mechanisms were classified as sudden deceleration prior to a change of direction or landing motion. here was the rate of anterior cruciate ligament injury higher in men in compare to the women during the study period. Men's football is a high-risk sport for anterior cruciate ligament injury. Unlike running, basketball, volleyball and gymnastics, The level of allowed contact in pivoting sports may be a factor in determining sport-specific anterior cruciate ligament risk.

Conclusions: We though that ACL tear is not uncommon in Makkah city population, although ACL still more common in male and in contact injury specially in football player. however protein diet and rehabilitation after surgery shown significance improvement in compare with patient not follow diet and rehabilitation.

Copy Right, IJAR, 2018,. All rights reserved.

\section{Introduction:-}

The anterior cruciate ligament (ACL) is essential to stabilizing ligament of the knee that is frequently hurt by sport and trauma victims. The prevalence rate between 100,000 and 200,000 every year in the United States ${ }^{[1,2]}$.

The knee joint is complex joint, which movement and stability are adjusted by the collaboration amongst passive and active structures. ${ }^{[3]}$ The defense systems of knee ligaments include intra-articular and periarticular collagen structures, which are supported by the neuromuscular system. [3]

Corresponding Author:- Maram Alrubayyi.

Address:- Medical Student, Tabuk University, College of Medicine, Tabuk City, Saudi Arabia. 
Anterior cruciate ligament (ACL) injuries are often possible aftereffect of low-speed, noncontact, deceleration injuries and contact injuries with a rotational part. Contact sports also may produce injury to the ACL secondary to turning, valgus stress, or hyperextension all directly related to contact or impact. ${ }^{[4,5]}$

Anterior cruciate ligament (ACL) injuries can occur by a different of mechanisms, including both high-energy and low-energy. Low-energy injuries may include contact mechanism .However, non-contact injuries are more typical, representing approximately 70 percent of ACL tears ${ }^{[6,7]}$. The most common mechanism is a low-energy, noncontact injury to $\mathrm{b}$ continuous during an sport movment.

Acute ACL injury is usually followed by pain, knee effusion, and muscular inhibition. ${ }^{[8]}$ Steady disability after the acute phase is attributed to expanded knee joint laxity and altered neuromuscular capacity, which may prompt to dynamic joint instability ${ }^{[8]}$.

The combination of pop sound during a rotational movement or fast sudden stop, together with powerlessness to proceed participation, and followed by early swelling, is said to demonstrate a $90 \%$ likelihood of rupture of the anterior cruciate ligament. ${ }^{[5]}$

the diagnostic accuracy of acute knee injuries in younger patients is not as much as that in adults ${ }^{[9,10,11]}$.The expanded difficulty in correctly diagnosing acute knee injuries in kids has been proposed to be partly because the naturally more prominent laxity in the knees of children, ${ }^{[10]}$ and the decreased sensitivity and specific city of magnetic resonance imaging (MRI)may likewise play a role. ${ }^{[9]}$ Advances in imaging study and expanded the awareness of ACL injuries in this populace will probably enhance diagnostic accuracy later on ${ }^{[12]}$. The combination of injury history, clinical examination, and imaging specially MRi is recommended to optimize the diagnostic accuracy of ACL injuries in skeletally immature people ${ }^{[11,13]}$.

Plain radiographs imaging are often performed after trauma to the knee injuries to rule out fractures, but can't be utilized to diagnose ACL tears. In some cases, an avulsion fracture of the anterolateral tibial plateau at the site of attachment of the lateral capsular ligament (the so-called Segond fracture) is recognized on plain film. Such an injury suggests the presence of an associated ACL rupture ${ }^{[14-15]}$.

In the United State, MRI is the essential modality used to diagnose ACL injury. In parts of Europe, ultrasound is frequently used to aid in the diagnosis. Knee arthrograms are just performed in patients in whom MRI is contraindicated and physical examination is uncertain.

MRI is both highly sensitive and specific in the diagnosis of complete ACL rupture. A systematic survey utilizing arthroscopy as the best quality level found MRI to have a sensitivity of 86 percent and a specificity of 95 percent for ACL tear ${ }^{[16]}$. Diagnostic studies, again utilizing arthroscopy as the gold standard, describe sensitivities as high as 92 to 100 percent and specificities as high as 95 to 100 percent ${ }^{[17,18]}$. MRI is less accurate in differentiating complete tears from partial tears, and in identifying chronic tears.

The main goal is to estimate the prevalence, risk factor and mechanism of Anterior Cruciate Ligament Injury among Makkah city, Saudi Arabia.

\section{Methodology:-}

Randomized cross-sectional study from the population of Makkah city, Saudi Arabia to determine the prevalence and mechanishm of ACL injuries. Carry out in 266 from the population were interviewed by questioner about the events surrounding their ACL along side with information on the gender, date of birth, date of injury, activity at the time of injury, place, diagnosis, situation of injury, treatment, sport and visits to the hospital . A written consent obtained from each; there was no names or phones or e-mail in the questionnaire. the samples were chosen randomly. A pilot study conducted to establish whether people or the investigators understand the questionnaires. The data was collected and arranged in tables analysis and entered in SPSS software version 23..

\section{Results:-}

There were 266 of knee injuries reported, 223 were male and 40 were a females. 266 patients shown the majority of them age between the 20 to 30 years represented $63.5 \%$, while age less than 20 years was $7.6 \%$, from 30 to 40 years $20.5 \%, 40$ to 50 years $6.1 \%$ and more than 50 years represent $2.3 \%$. 
The ACL injury rate in women shown $15.2 \%$, although it was less than that of the men's rate $84.8 \%$. The difference in the ACL injury rate between the gender was obvious in both practices and games.

The mechanism of their injuries reported mainly in the sports, for instance football represents $78.2 \%$, running $8.4 \%$, basketball $0.4 \%$, volleyball $2.1 \%$, gymnastics $0.4 \%$ (Table 1,2 ). 18 cases of the ACL injury occurred due to a sudden increase in running while 20 cases occurred due to stop running suddenly, 14 cases of them did not report the exact mechanism of their injury. On other hand 16 cases were listed as road traffic accident and 14 cases as related to environmental injury (i.e. work related ).

The diagnostic tools of an ACLI were confirmed by Magnetic Resonance Imaging 67.4\%, 51.7\% were confirmed by physical examination.

This research reported injury as the following : partial anterior Cruciate Ligament injury $23.7 \%$, complete anterior Cruciate Ligament injury $37.9 \%$, partial posterior cruciate ligament injury $6.3 \%$, complete posterior cruciate ligament injury $4.5 \%$, lateral Collateral Ligament injury $13.8 \%$, internal cartilage injury $26.3 \%$, external cartilage injury $15.6 \%$.

Patients who have been suffering from the injury have experienced with these following symptoms; sharp pain $66.9 \%$, swelling $52.9 \%$, redness $19.4 \%$, pop sound $57 \%$, joint lock $37.6 \%$, joint stiffness $17.5 \%$, joint dislocation $5.7 \%$ and some of them present with nerve injury like numbness $12.2 \%$ and weakness $25.1 \%$, while other patients represent with unusual symptoms like high-grade fever, sore throat and skin rash. the majority of the patient describe the pain 8 out of $10(18.6 \%)$ (Figure 1). Patients who were under diet and rehabilitation during the injury were represented by $18.7 \%$, these patients reported they have less duration of pain, variety between less than 1 week $22.1 \%$ and from 1 to 2 weeks $30 \%$, whilst patients who do not follow the diet and rehabilitation they have longer in the duration of the pain and could be reached up to 2 months and less duration of recovery $18.1 \%$.

$31.6 \%$ they have a history of previous surgery repair of ACL injury. Chronic diseases have not had a significant impact on the ACL injury $90.9 \%$.

$21.7 \%$ they deny visited the clinic during the injury period, on another hand, $33.5 \%$ of the patients reported the pain got worse.

On treatment options this cases were treated by physiotherapy alone $37.6 \%$, surgery $14.1 \%$, combination of physiotherapy and surgery $39.7 \%$ and $8.5 \%$ of the cases still not receive a medical support with unknown reason.

Table 1:-Causes of anterior cruciate ligament (ACL) injuries

\begin{tabular}{|l|l|l|l|l|l|l|}
\hline Cause of injury & RTA & Works & Sports & Increase running & Stop running suddenly & Others \\
\hline No. of cases & 16 & 14 & $\underline{181}$ & 18 & 20 & 14 \\
\hline Percentage & $6.1 \%$ & $5.3 \%$ & $\underline{68.8 \%}$ & $6.8 \%$ & $7.6 \%$ & $5.3 \%$ \\
\hline
\end{tabular}

Table 2:-Work filed that cause anterior cruciate ligament (ACL) injuries

\begin{tabular}{|l|l|l|l|l|}
\hline Working field & Government Sector & Military sector & Private & Others \\
\hline No. of cases & $\underline{75}$ & 21 & 45 & 47 \\
\hline Percentage & $\underline{39.9 \%}$ & $11.2 \%$ & $23.9 \%$ & $25 \%$ \\
\hline
\end{tabular}

Table 3:-Type of sports that cause Anterior cruciate ligament (ACL) injuries

\begin{tabular}{|l|l|l|l|l|l|l|l|}
\hline $\begin{array}{l}\text { Type of } \\
\text { Sports }\end{array}$ & Football & Basketball & Volleyball & Gymnastics & Athletics & Running & Others \\
\hline No. of cases & $\underline{187}$ & 1 & 5 & 1 & 5 & 20 & 20 \\
\hline Percentage & $\underline{\mathbf{7 8 . 2} \%}$ & $0.4 \%$ & $2.1 \%$ & $0.4 \%$ & $2.1 \%$ & $8.4 \%$ & $8.4 \%$ \\
\hline
\end{tabular}




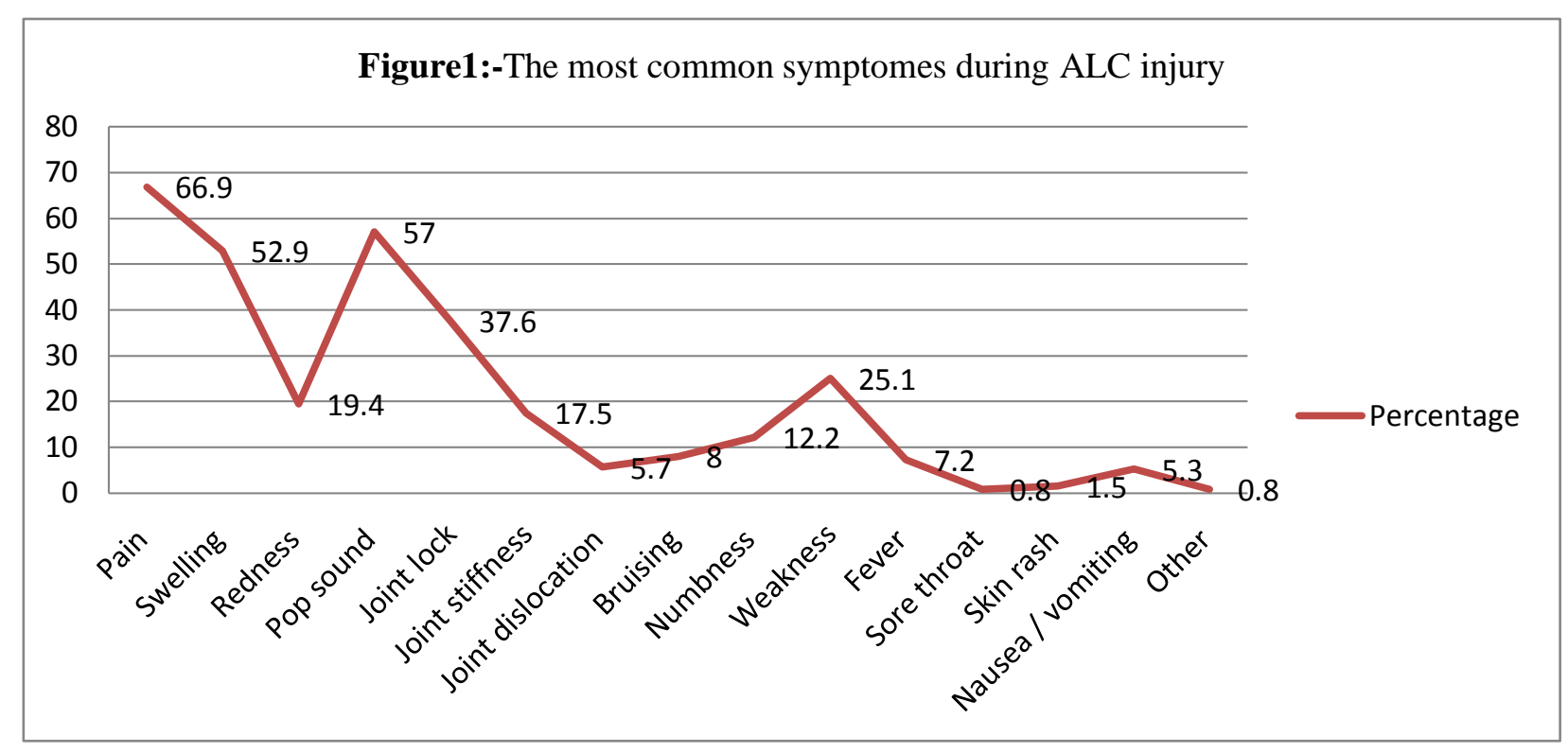

\section{Discussion:-}

De Loës, et al. ${ }^{[19]}$ reported that the combined number of anterior and posterior cruciate ligament injuries was 357 in boys and 113 in girls among participants in sports activities aged between the 20 to 30 years (63.5\%). Even though our data focused only on ACL injuries. The differences in data collection methods or in the race may explain this difference. Parkkari, et al. ${ }^{[20]}$ reported that participation in organized sports activity (>4 times/week) increased the rate of ACL injury. Some coaches and teachers in Saudi Arabia may impose very long training or practice schedules on young athletes because of the principle of victory supremacy in Saudi culture. Therefore, the amount of activity could have a direct related to the rate of ACL injury here.

The results of this study showed that the rate of ACL injury was highest among 20 - 30 year-olds (63.5\%) for both boys and girls. Previous studies reported that there is no tendency for the age of ACL injury occurrence. ${ }^{[1,20,21,22]}$ The results of this study demonstrated that man's had a 5.3-fold greater incidence rate of ACL injuries than did females. Previous studies have also reported gender differences in the incidence risk of ACL injury. ${ }^{[6,23,24]}$ Gender differences in anterior cruciate ligament injury vary with activity. A research reported ${ }^{[23]}$ that a 2.1-fold greater incidence rate of ACL injuries in girls than in boys among high school and college athletes. Another research that reported ${ }^{[24]}$ a 4.5 -fold greater incidence in girls than in boys among high school athletes. Also, another research reported ${ }^{[25]}$ that the ACL injury rate, excluding male-only sports in military academies, was 1.51-fold greater in women. The difference from the current study may due to lack or decrease of the female sports.

The results of this study also indicate that the greatest rate of ACL injuries was observed in sport football players, so the direct contact was common cause in this research in compared to the non-contact cause. A research was done reported that [26] the most severe injury during sport was the anterior cruciate ligament (ACL) ruptures (time loss: $4 \%$ of cases 3-6 weeks, 6\% 6-12 weeks, 26\% 3-6 months, 32\% 6-9 months, $18 \%$ 9-12 months, $14 \%>12$ months.

\section{Conclusions:-}

In this study shown the epidemiological data has been shown differences number of injuries and among males and females in activities. Particularly, strong epidemiological data support increased prevalence of non-contact anterior cruciate ligament injuries.

\section{Conflict Of Interests:-}

The authors have no conflict of interests to disclose. 


\section{References:-}

1. Gordon MD, Steiner ME. Anterior cruciate ligament injuries. In: Orthopaedic Knowledge Update Sports Medicine III, Garrick JG. (Ed), American Academy of Orthopaedic Surgeons, Rosemont 2004. p.169.

2. Albright JC, Carpenter JE, Graf BK, et al. Knee and leg: soft tissue trauma. In: Orthopaedic Knowledge Update 6, Beaty JH. (Ed), American Academy of Orthopaedic Surgeons, Rosemont 1999. p.533.

3. Ellison A, Berg E. Embryology, anatomy, and function of the anterior cruciate ligament. Orthop Clin North Am 1985;16:3-14.

4. AAOS. Management of Anterior Cruciate Ligament Injuries: Evidence-Based Practice Guideline. American Academy of $\quad$ Orthopaedic $\quad$ Surgeons. Available athttp://www.aaos.org/Research/guidelines/ACLGuidelineFINAL.pdf. Accessed: May 302017

5. Bytomski J, Moorman C (2010). Oxford American Handbook of Sports Medicine. Oxford American Handbook of Medicine Series (First ed.). Oxford, New York: Oxford University Press. p. 290.ISBN 9780195372199.

6. Mountcastle SB, Posner M, Kragh JF Jr, Taylor DC. Gender differences in anterior cruciate ligament injury vary with activity: epidemiology of anterior cruciate ligament injuries in a young, athletic population. Am J Sports Med 2007;35:1635.

7. Boden BP, Dean GS, Feagin JA Jr, Garrett WE Jr. Mechanisms of anterior cruciate ligament injury. Orthopedics. 2000; 23:573-8.

8. Palmieri-Smith RM, Kreinbrink J, Ashton-Miller JA, Wojtys EM. Quadriceps inhibition induced by an experimental knee joint effusion affects knee joint mechanics during a single-legged drop landing. Am J Sports Med. 2007;35:1269-1275.

9. Kocher MS, DiCanzio J, Zurakowski D, Micheli LJ. Diagnostic performance of clinical examination and selective magnetic resonance imaging in the evaluation of intraarticular knee disorders in children and adolescents. Am J Sports Med. 2001;29:292-296

10. Lee K, Siegel MJ, Lau DM, Hildebolt CF, Matava MJ. Anterior cruciate ligament tears: MR imaging-based diagnosis in a pediatric population. Radiology. 1999;213:697-704.

11. Major NM, Beard LN, Jr., Helms CA. Accuracy of MR imaging of the knee in adolescents. AJR Am J Roentgenol. 2003;180:17-19

12. Kim HK, Laor T, Shire NJ, Bean JA, Dardzinski BJ. Anterior and posterior cruciate ligaments at different patient ages: MR imaging findings. Radiology. 2008;247:826-835.

13. Benjaminse A, Gokeler A, van der Schans CP. Clinical diagnosis of an anterior cruciate ligament rupture: a meta-analysis. J Orthop Sports Phys Ther. 2006;36:267-288.

14. Dietz GW, Wilcox DM, Montgomery JB. Segond tibial condyle fracture: lateral capsular ligament avulsion. Radiology 1986; 159:467-9.

15. Cosgrave CH, Burke NG, Hollingsworth J. The Segond fracture: a clue to intra-articular knee pathology. Emerg Med J 2012;29:846-7.

16. Spindler KP, Wright RW. Clinical practice. Anterior cruciate ligament tear. N Engl J Med. 2008;359:2135-42.

17. Lee JK, Yao L, Phelps CT, Wirth CR, Czajka J, Lozman J. Anterior cruciate ligament tears: MR imaging compared with arthroscopy and clinical tests. Radiology 1988; 166:861-4.

18. J M Mellado, J Calmet, M Olona, J Giné, A Saurí. Magnetic resonance imaging of anterior cruciate ligament tears: reevaluation of quantitative parameters and imaging findings including a simplified method for measuring the anterior cruciate ligament angle. Knee Surg Sports Traumatol Arthrosc.2003;12:217-244.

19. de Loës M, Dahlstedt LJ, Thomée R. A 7-year study on risks and costs of knee injuries in male and female youth participants in 12 sports. Scand J Med Sci Sports. 2000;10:90-7.

20. Parkkari J, Pasanen K, Mattila VM, Kannus P, Rimpelä A. The risk for a cruciate ligament injury of the knee in adolescents and young adults: a population-based cohort study of 46500 people with a 9 year follow-up. Br J Sports Med. 2008;42:422-6.

21. Yu B, Kirkendall DT, Taft TN, Garrett WE Jr. Lower extremity motor control-related and other risk factors for noncontact anterior cruciate ligament injuries. Instr Course Lect. 2002;51:315-24.

22. Shea KG, Pfeiffer R, Wang JH, Curtin M, Apel PJ. Anterior cruciate ligament injury in pediatric and adolescent soccer players: an analysis of insurance data. J Pediatr Orthop. 2004;24:623-8.

23. Beynnon BD, Vacek PM, Newell MK, Tourville TW, Smith HC, Shultz SJ, et al. The Effects of Level of Competition, Sport, and Sex on the Incidence of First-Time Noncontact Anterior Cruciate Ligament Injury. Am J Sports Med. 2014;42:1806-12.

24. Renstrom P, Ljungqvist A, Arendt E, Beynnon B, Fukubayashi T, Garrett W, et al. Non-contact ACL injuries in female athletes: an International Olympic Committee current concepts statement. $\mathrm{Br} \mathrm{J}$ Sports Med. 2008;42:394-412. 
25. Mountcastle SB, Posner M, Kragh JF Jr, Taylor DC. Gender differences in anterior cruciate ligament injury vary with activity: epidemiology of anterior cruciate ligament injuries in a young, athletic population. Am J Sports Med. 2007;35:1635-42.

26. Akoto R, Lambert C, Balke M, et al Epidemiology of injuries in judo: a cross-sectional survey of severe injuries based on time loss and reduction in sporting level Br J Sports Med Published Online First: 26 April 2017. doi: 10.1136/bjsports-2016-096849 